\title{
EVALUATION OF DEMOGRAPHIC AND SOCIO-ECONOMIC FACTORS OF MORTALITY IN THE SOUTH MORAVIAN REGION (CZECH REPUBLIC)
}

\author{
Dana Hübelová1, Alice Kozumplíková1 \\ ${ }^{1}$ Faculty of Regional Development and International Studies, Mendel University in Brno, Zemědělská 1, \\ 61300 Brno, Czech Republic
}

To link to this article: https://doi.org/10.11118/actaun201967051255

Received: 27. 5. 2019, Accepted: 6. 9. 2019

To cite this article: HÜBELOVÁ DANA, KOZUMPLÍKOVÁ ALICE. 2019. Evaluation of Demographic and Socioeconomic Factors of Mortality in the South Moravian Region (Czech Republic). Acta Universitatis Agriculturae et Silviculturae Mendelianae Brunensis, 67(5): 1255-1267.

\begin{abstract}
The main objectives of the article were: a comparison of the demographic and SE indicators in the South Moravian Region, a study of the development of demographic and SE indicators in the South Moravian Region in the years 2006-2015 and the clustering of similar districts on the basis of demographic and SE indicators as well as mortality and its main causes. The set of aspects affecting the structure of mortality represented 12 demographic factors and 2 socio-economic factors. The results of the composite indicator and the beta convergence indicate that the positive development of the analysed factors was mainly achieved by the Vyškov District and the Brno-Country District, while negative development was observed in the Břeclav District. The cluster analysis was based on four clusters: cluster 1 (Břeclav, Hodonín and Znojmo districts) showed below-average values of the demographic and the socio-economic indicators with a relatively favourable mortality rate based on causes of death; cluster 2 (Blansko and Vyškov districts) was classified as average; cluster 3 (mainly including the Brno-Country District) was seen as the best and cluster 4 (mainly including the BrnoCity district) was observed to have negative development.
\end{abstract}

Keywords: cause-specific death rate, demographic and socio-economic determinants, cluster analysis, South Moravian Region

\section{INTRODUCTION}

Population mortality and morbidity, their structural and spatial distribution, development over time and overall monitoring, are key issues of health geography, epidemiologic surveys and policy formation in the area of public health (Lee et al., 2009). Analyses of mortality and morbidity serve as a starting point for the planning and development of effective interventions focused on a reduction of inequalities in the health condition of the population, in both its structural and spatial aspects (Marmot et al., 2008). Demographic and socio-economic (SE) determinants are generally considered as one of the main groups of factors affecting not only health, morbidity and mortality rates but also the overall quality of life of the population (Tobiasz-Adamczyk et al., 2011). These factors are determined not only by the social structure but also by the spatial structure on various regional scale levels (Barton \& Grant, 2006; Borrell et al., 2013). Recently, especially international references have revealed a shift of the research from the national and regional to the intra-regional or even local scale (Luck et al., 2006; 2014). 


\section{Theoretical Assumptions}

In terms of the theoretical assumptions, a brief definition of the key determinants of mortality, the development and status of mortality in the Czech Republic and the purpose of mortality indicator monitoring are presented. Mortality is an important factor of demographic processes and analyses of morbidity, while mortality and the cause-specific death rate are the main values indicating the health condition of the population (Fraser and George, 2015). Mortality is also considered one of the key indicators of the success or failure of national development reflecting the ability of the society to transform the economic capital to the health of its population (Shkolnikov et al., 2004). Mortality and morbidity in general are determined by a number of factors (Lundquist et al., 2014):

1) genetic and demographic,

2) environmental factors represented by climatic conditions and the environment,

3) socio-economic and cultural.

These factors are determined by al and the social conditions of the environment in which the people live, with a subsequent effect on the social and community networks and individual lifestyle factors (Dahlgren and Whitehead, 1991). A number of such factors appear to influence mortality, morbidity and the overall health condition of the population, with the manifestation of the effect in a long-term horizon, sometimes. Simply speaking, the current health condition of the population and its determinants form the future resultant of the general mortality level and cause-specific death rate (Barton and Grant, 2006).

The level of mortality in the Czech Republic has improved since 1989. This can be explained by the mutual interactions of multiple agents, with the major ones including the improved quality of healthcare along with a number of related aspects (the use of modern therapeutic procedures, technologies etc.), in addition to direct healthcare. The situation is further improved by the orientation of the population towards a healthy lifestyle, a broader portfolio of food, the transfer of the economically active population from the industrial to the service sector, a more favourable environment quality etc. (Hübelová, 2014a).

In the international context, the mortality level in the Czech Republic continues to be unsatisfactory, reaching below-average values in the EU context. The standardized mortality rate in the Czech Republic was $20 \%$ or $19 \%$ above the EU mean in the male and female population, respectively (IHIS CR, 2015). The cause-specific death rate is classified and coded pursuant to the "International Statistical Classification of Diseases" published by WHO (WHO, 2011). The structure of the cause-specific death rate in advanced countries is dominated by non-communicable diseases (NCD), a disease class to a large extent affected by lifestyle (Muniz et al.,
2012). The diseases representing the man causespecific death rate include (1) circulatory system diseases (chapter IX); (2) neoplasm (chapter II); (3) respiratory diseases (chapter X); (4) digestive system diseases (chapter XI) and (5) external causes of death (chapter XX). Like all advanced countries, the Czech Republic cannot manage to achieve an improvement in the occurrence of NCD as direct consequences of an unhealthy lifestyle (Arruda et al., 2015).

NCD represent a serious health issue in advanced countries with all its socio-economic consequences. The occurrence of new deaths for NCD with increasing age grows from middle age on up with a culmination in the 50 and over age groups (NIPH, 2015a). The most frequent cause-specific death rate in the Czech Republic is represented by circulatory system diseases (accounting for about 50\% of all deaths, mainly in the form of circulatory system diseases), followed by malignant tumours (around 25\%; IHIS CR, 2016). Although the mortality of the circulatory system diseases has successfully been slightly reduced, this indicator is still high in comparison to the EU 15 mean (about twice as high). The increasing prevalence of chronic forms of circulatory system diseases and the virtually constant mortality rate connected with these diseases is a consequence of improved medical care, paradoxically enough (Bruthans, 2000). The incidence of tumour diseases has grown in the past decade by $5.8 \%$ in males and $6.1 \%$ in females, with a rather constant mortality rate (Ministry of Health CR, 2014). The recent rate of deaths for respiratory diseases in the Czech Republic amounts to less than $6 \%$ in males and $4.7 \%$ in females and is equal to the EU mean, although there are countries with considerably lower rates of deaths caused by respiratory diseases (for example Austria or Sweden). Mortality caused by digestive system diseases is slightly higher in the Czech Republic in comparison to EU Member States but its share in total mortality is relatively low (Ministry of Health CR, 2014).

A very strong effect of demographic and socioeconomic factors on the health state and mortality of the population is currently considered to be established (Marmot et al., 2008; Marmot and Bell, 2012). Demographic and SE determinants are used by large national and international comparative studies of health and health condition (EC, 2012; Börsch-Supan et al., 2013; Minicuci et al., 2016). Published study results include indicators of gender and age structure, education level or gross national or domestic product (GNP/GDP) per capita (Khang et al., 2010) in the demographic and SE predictors. The often discussed mortality determinants are those on the macro level, such as in connection with the incurred costs of public health or GDP of selected countries (Jürges, 2007; Swift, 2011). However, above a certain GDP level, the correlation between 
economic progress and health or mortality weakens (Clark, 2011). The reason is that the GDP indicator does not cover the territorial distribution of income within the society on the territorial micro level and yet it is income that is clearly a significant context determinant of population health and morbidity in developed (for example European) countries (Brandt et al., 2012). An important question then is when and how individual income is reflected in the inequality of health over the course of human life and death at its end. For that reason, a shift of the relevant research from the national and regional to the intra-regional or local level (Luck et al., 2006) is observed. Torre and Myrskylä (2011) have discovered that increased income inequality increases the infant and child mortality rate, but were unable to identify the responsible underlying mechanism (the assumptions may include, for example, a lack of social services or the stress of the parents). While most studies of income inequality focus on the current situation, Subramanian and Kawachi (2004) have pointed to the existence of delayed effects of income inequality.

Epidemiological studies focus on demographic factors of mortality (gender, age, education, occupation, unemployment, marital status etc.) and SE effects (the social status of an individual in his/her job and in the society, economic condition, income, health literacy, availability of healthcare etc.). There is a clear link to the socio-economic status (SES; Glazier et al., 2014; Fraser, George, 2015; Minicuci et al., 2016). For that reason, one may say that health, health condition and mortality level in effect follow SES gradients. Many research and study reports prove that individuals with lower SES show higher morbidity, handicap, premature death and mortality in general and they suffer from diseases more often in the course of their lives, which is also reflected in a shorter healthy lifespan and overall survival chances (NIPH, 2015b). On the other hand wealthier and educated individuals are healthier than less educated individuals living in relative poverty (Frank et al., 2003; Matthews et al., 2005). The SE gradient in health, well documented in many countries, can be seen in this connection (Veugelers et al., 2001).

The current SES of an individual is a significant prerequisite for the further development of his/ her health condition and subsequent successful aging (extension of healthy life years, active leisure, participation in community life, etc.). This is proved by studies describing current demographic and SE characteristics and other circumstances of SES, especially in the senior age group (McLaughlin et al., 2010). Other studies also suggest that SES factors applied in the past (such as family background, SES in childhood, job status etc.) show a substantial and long-term effect not only on individual health (Pruchno et al., 2010; Brandt et al., 2012) but also on the level of mortality (Galobardes,
2004; Frijters et al., 2010). Recent publications also mention evaluations of the relationship between morbidity and a high infant and child mortality rate or between mortality and economic recession in childhood (Berg et al., 2009; Portrait et al., 2010; Delaney et al., 2011). Survival chances differ considerably depending on where the individual is born and brought up. Thus the survival chances are differentiated by county as well as by smaller geographical units. There is also a certain social transition showing that the lower the SE position, the worse the health condition (Marmot et al., 2008).

\section{Research Objectives and Study Area}

The main objectives were:

1) a comparison of demographic and SE indicators in the South Moravian Region (SMR) with the help of the composite indicator,

2) a study of the development of demographic and SE indicators in the South Moravian Region in the years 2006-2015 with the application of the convergence method,

3) clustering similar districts on the basis of demographic and SE indicators and mortality and its main causes in the timeline 2006-2015 with the help of cluster analysis.

The SMR consists of seven districts - LAU1 (Blansko, BL; Brno-City, BM; Brno-Country, BV; Břeclav, BR; Hodonín, HOD; Vyškov, VYS; Znojmo, ZNM) and borders Slovakia in the east and Austria in the south, and the South Bohemian, Vysočina, Pardubice, Olomouc and Zlín regions of the Czech Republic, in the direction from the western to the north-eastern boundary of the region (Fig. 1). The SMR with its area of 7,188 $\mathrm{km}^{2}$ is the fourth largest region of the Czech Republic.

Despite their relatively small size, SMR districts are relatively distinct and unique, due to natural, historical and economic characteristics, which are subsequently reflected in specific demographic features and various socio-economic profiles (district characteristics can be found in more detail in Hübelová, 2014b). Blansko District (BL) is one of the least populous ones in the region. The economy in the district has always had an industrial-agricultural character. Engineering, with its 100-year tradition, is the most important of the industrial sectors. Employment in the Blansko District is generally facilitated by the easy transport accessibility of Brno companies (the railway corridor). The age structure of the district and the age index are average with respect to the nationwide indicator. The minor population decline by natural population change (the mortality rate slightly outweighs the birth rate) is at least partially offset by migration growth.

Brno-City District (BM) is a traditional commercial and cultural center of SMR, it is the second largest education center in the Czech Republic and also a regional health center. Brno-City District is 


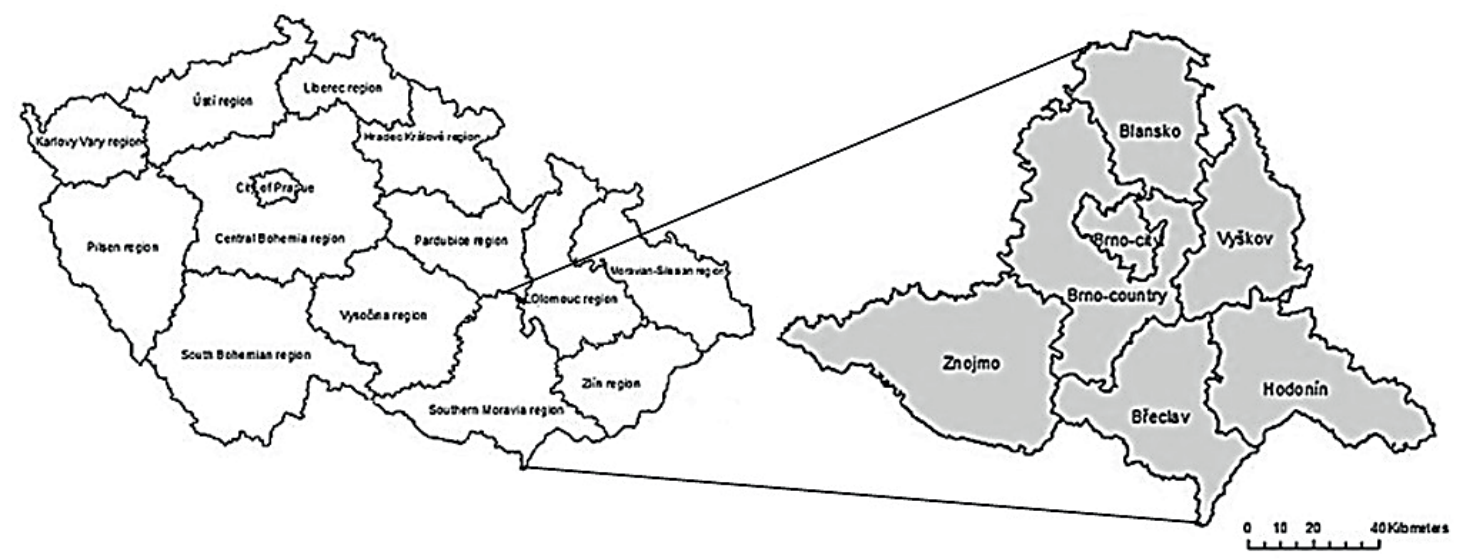

1: Administrative breakdown of the South Moravian Region Source: own elaboration

characterized by the trend of suburbanization, where the inhabitants working in the city move to suburban zones. The unemployment rate is relatively low and is conditioned by the sectoral structure of the regional economy, transport accessibility and the quality of local infrastructure. As a result of suburbanization, the average age index is above average, and the relatively favorable fertility rate is not enough to mitigate the aging process. The Brno-City District is characterized by a decrease in population, as both the natural and migration growth is negative, while migration decline exceeds the natural loss. The educational structure is very favorable, especially the aboveaverage share of people with university education.

The Brno-Country District (BV) is the second largest in terms of population in the SMR and its size is gradually increasing. An important role for this is played by immigrants from the Brno-City District, taking advantage of the good conditions for construction in the quiet environment of the municipalities of the Brno-Country District with relatively good transport links to the regional city of Brno. The registered unemployment rate has long been one of the lowest in the region, which is also due to the fact that the inhabitants of the district find employment opportunities, especially in the city of Brno. In the Brno-Country District, due to the suburbanization process, the age groups under 14 years and over 65 are practically balanced and the age index is low. In the characteristics of natural and migration movement, the Brno-Country District exhibits growth, which is reflected in the significantly positive overall growth while the educational structure is also at a very good level.

Due to favorable soil and climatic conditions, the Břeclav District (BR) has historically had a strong tradition in agriculture. Due to the rather peripheral location and the agricultural character of the district, there is an increased unemployment rate associated with the lower educational level of the population, especially in smaller municipalities below 1 thousand residents. The age structure of the population with a below-average age index is relatively favorable. Both natural and migration growth, and thus total growth, have had slightly positive and balanced values in the long term. In the district, there is an increased number of recipients of social benefits, which are indicators of the potential occurrence of social exclusion.

The Hodonín District (HOD) is a typical peripheral location on the Moravian-Slovak borderland. The demise, or various transformations of large industrial enterprises, which were among the main employers in the past, is reflected in the high unemployment rate, which in the long term is one of the highest in the Czech Republic in the interdistrict comparison.

This is one of the reasons for the negative migration balance, when labor migration from the district also results in a negative natural increase and declining population. These phenomena are also accompanied by an increasing age index.

The economy in the Vyškov District (VYS) traditionally has an industrial-agricultural character. Employment is greatly aided by the historically easy transport accessibility of Brno businesses and at present the city of Brno has emphasized this task even more. The district has a favorable age structure, shows a positive natural and migration increase and thus a positive total increase of the population along with a favorable educational structure. Similarly, to the Brno-Country District, the Vyškov District is also influenced by new housing construction and the continuing trend of suburbanization

The Znojmo District (ZNM) lies on the MoravianAustrian border and is one of the agro-industrial regions with slightly prevailing agriculture. Due to the generally low industrialization of the district, the absence of large enterprises and the seasonality of some activities, the district achieves high unemployment. This is, among other things, the reason for the very low natural, migration and 
hence overall increase, which in some years shows negative values. At the same time, the educational structure and the increasing value of the old age index are not very favorable.

The purpose of the research was to analyse demographic and SE indicators which might be considered complex indicators (determinants) representative of the theoretical model of mortality indicators:

1) demographic indicators: standardized mortality rate by the most frequent cause-specific death rate (circulatory system diseases, respiratory and digestive system diseases and external causes of death; chosen standard SMR), aging index, neonatal mortality rate, the percentage of children with a birth weight below $2.5 \mathrm{~kg}$, the total abortions /livebirths ratio and the proportion of spontaneous miscarriages,

2) SE indicators: percentage of the unemployed in the 15-64 age group and the proportion of paid out housing allowances per person.

Mortality is a significant factor of demographic processes and analyses of mortality by the main cause-specific death rate are one of the main values showing the health condition of the population (Ward, 2012; OECD, 2013). Mortality is an indicator of state success reflecting economic standards and their transformation to population health (Shkolnikov et al., 2004). The age structure of the population expressed by the aging index results from the long-term progress of the basic demographic processes (Ďurček and Richter, 2014). But at the regional level LAU1, the aging index affects other factors such as the trend of suburbanization. The effect of suburbanization is to rejuvenate the age structure, because higher mobility is exhibited by people in an economically younger age and who are more educated (Hübelová, 2014a). Neonatal and infant mortality rate are considered to be an indicator of the region's economic maturity, standards of healthcare and lifestyle, along with the proportion of children with a birth weight below $2.5 \mathrm{~kg}$ (Galobardes et al., 2004). The abortion and spontaneous miscarriage percentage is one of the demographic phenomena significantly contributing to the health of the population (Norsker et al., 2012).

Significant SE determinants include the position on the job market. The health consequences of unemployment are extensive, beginning with mental disease and ending with circulatory system diseases (Shumaker et al., 2009). The negative effects of unemployment are direct, manifested by depression or a loss of self-confidence, connected with a worsened quality of life (Hübelová, 2014c). The proportion of paid out housing allowances per person is an indicator of the scope and depth of poverty (Ouředníček et al., 2011). This indicator may be used for the monitoring of areas with higher concentrations of an SE-weak population, pointing out the social deprivation of territories (McGuinness et al., 2012) and an assessment of spatial differentiation in household income (Hübelová, 2014a), which in turn influence morbidity, mortality and other demographic indicators.

\section{MATERIALS AND METHODS}

\section{Data Collection and Methods}

The panel data for this paper was used involving measurements from the seven SMR (BL, BM, BV, BR, HOD, VYS, ZNM) over the years 2006-2015 (Fig. 1). The selection of variables (of a cardinal nature) was done purposefully with the a-priori belief that these might contribute to the construction of the standardized cause-specific mortality (expressed as $\%$ and calculated as a summation indicator from circulatory system, respiratory and digestive system diseases, neoplasm as well as external causes of mortality) and a socio-demographic profile encompassing variables as follows: death rate (\%o; deaths per 1,000 members of the population), aging index (\%), neonatal and infant mortality rate (\%o; dying in 28 days, or within the first year of life per 1,000 live births), spontaneous abortion rate (per 100 of all abortions), abortion rate (per 100 live births), the rate of children with a live birth under $2.5 \mathrm{~kg}$ (per 100 live births), unemployed people aged 15-64 in the population (\%), the proportion of paid out housing allowances per person (CZK/ allowance).

The source for all data used in this paper was the Czech Statistical Office (CSO, 2016a; 2016b; 2016c) over the years 2006-2015.

To support the primary target of the paper, the partial objectives to be addressed were threefold:

1) to construct a composite indicator involving sub-indicators (described above) to capture a collective socio-demographic mind-set of SMR using the min-max method of standardization with the range of values $<0 ; 100>$ and the simple average approach for aggregation;

2) to investigate whether the districts converged/ diverged in the years 2006-2015 in terms of the socio-demographic profile using beta (based on a slope of fitted regression line) and sigma (based on standard deviations) approach. More specifically, the beta approach assumes units to converge if originally low values grew faster (as measured by geometric mean) than originally high values. On the other hand, the sigmaconvergence takes place if the dispersion of units (as measured by standard deviations) declines over time;

3) to establish groupings of districts in the years 2006-2015 with respect to the cause-specific mortality and the demographic and SE profile by means of both hierarchical (based on Ward's method using squared Euclidean distance) and non-hierarchical (based on k-means) cluster 
analysis. More specifically, the Ward's method was carried out first to determine the number of clusters which served then as seed points for the k-means method generating the final cluster solution.

\section{RESULTS}

Before running the analysis, the correlation matrix was inspected first to identify substantial correlations $(\mathrm{R}>0.8)$ as these might distort the composite indicator. Owing to this, the neonatal mortality rate was eliminated as it highly correlated with the infant mortality rate $(\mathrm{R}=0.84)$. Furthermore, the variables were checked for possible skewness and kurtosis (as measured by corresponding coefficients), however, as these were rather low, the data were not submitted to any transformations.

In the next step, it was examined whether districts converge or diverge over time. Using the beta approach, it may be concluded that despite the slight negative slope (b1 $=-0.0013$ ) pointing to the weak convergence, the tendency cannot be deemed as substantial as the index of determination tends to be low $\left(\mathrm{R}^{2}=28.32 \%\right)$. Despite that, there are development trends in the assessed demographic and SE indicators in the period 2006-2015 in the individual districts and towards the status of the monitored indicators in 2015. The highest value of the composite indicator 67.8 compiled from the demographic and SE determinants was achieved in 2015 by the BV district, followed by BL with the value of 55.6 and VYS with the value of 55.5. The worst rank was occupied by the HOD district with its composite indicator value of 47.7 and BR with the value of 45.5 (Tab. I).

The positive development of the composite indicator can mainly be seen in the VYS district, which achieved the highest improvement of its demographic and SE indicators in the period in question. Although the initial value of the composite indicator in 2006 was the lowest in comparison to all SMR (below 40), it increased to more than 55 by 2015. The highest value of the composite indicator was achieved by the BV district, but the improvement dynamics were not as high (1.014) as in the case of the VYS district (1.038). On the

I: Resulting values of beta-convergence in the period 2006-2015 and geometric mean (districts of the South Moravian Region in 2006-2015)

\begin{tabular}{|c|c|c|c|c|c|c|c|c|c|c|c|}
\hline$\frac{\text { year }}{\text { district }}$ & 2006 & 2007 & 2008 & 2009 & 2010 & 2011 & 2012 & 2013 & 2014 & 2015 & geo-mean \\
\hline BL & 50.431 & 62.886 & 59.617 & 55.635 & 56.830 & 52.810 & 47.265 & 55.272 & 56.000 & 55.618 & 1.011 \\
\hline $\mathrm{BM}$ & 47.968 & 49.270 & 55.930 & 52.364 & 46.272 & 51.159 & 43.174 & 43.338 & 41.367 & 50.352 & 1.005 \\
\hline BV & 59.628 & 68.993 & 70.535 & 63.891 & 70.334 & 58.119 & 57.511 & 54.981 & 61.151 & 67.755 & 1.014 \\
\hline BR & 53.319 & 65.566 & 63.965 & 53.805 & 48.915 & 48.610 & 37.861 & 51.176 & 40.166 & 45.511 & 0.983 \\
\hline VYS & 39.527 & 60.112 & 64.785 & 58.819 & 60.393 & 55.126 & 57.029 & 52.563 & 51.296 & 55.501 & 1.038 \\
\hline HOD & 44.750 & 56.871 & 57.315 & 43.829 & 41.196 & 41.859 & 49.422 & 36.796 & 42.347 & 47.659 & 1.007 \\
\hline ZNM & 44.020 & 64.194 & 61.345 & 54.780 & 41.629 & 41.343 & 47.530 & 40.167 & 42.417 & 50.867 & 1.016 \\
\hline
\end{tabular}

Source: own elaboration on the basis of data of the Czech Statistical Office 2016a; 2016b; 2016c

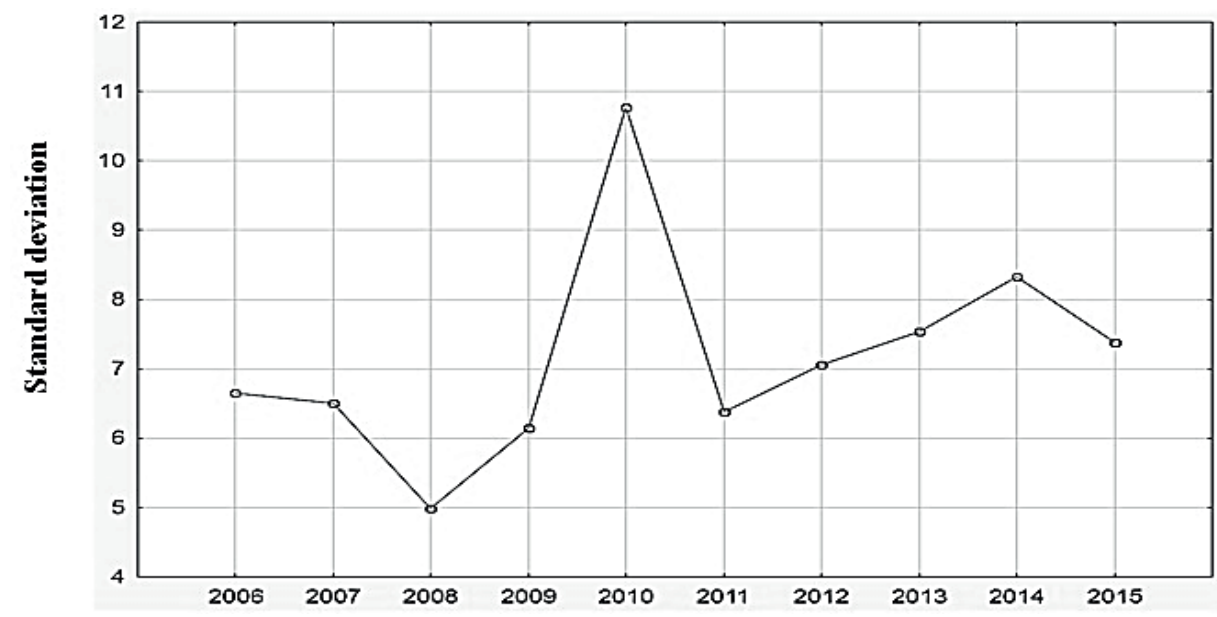

2: Fitted regression line of districts (the South Moravian Region in 2006-2015) Source: own elaboration 
other hand, the worst development of the analyse indicators was shown by the BR district, where demographic and SE conditions worsened and the composite indicator value decreased from 53 in 2006 to 46 in 2015 (Tab. I). The other districts (BL, BM, HOD and ZNM) formed a cluster with similar values of the composite indicator and the geometrical mean (Fig. 2).

The line plot revealed alternating tendency over time as demonstrated by declining standard deviations in the years 2006-2008, reaching its peak value in year 2010 followed by a rise in years 20102014. In other words, besides the dramatic change in year 2010, the dominating tendency seems to be rather divergence in recent years indicating deepening demographic and SE disparities among districts (Fig. 3).

Last but least, the organization of districts over time into 4 clusters (Tab. II) was performed.

Clusters were then described along cause-specific mortality and demographic and SE indicators using a profile diagram with means and error bars (with the length of whiskers equal to one standard deviation; Fig. 4).

Cluster 1 is typified with the lowest cause-specific mortality, however, at the same time with the worst demographic and SE performance. This mainly applies to the districts of BR, HOD, ZNM in the border area of both the SMR and the Czech Republic. Within the monitored period (calendar years) this cluster of districts mainly unified in the years 20122014. Although the age structure of these districts is relatively favourable, and most likely affects the relatively positive situation in mortality by cause of death, the real cause is rather the echo of the transfer of the younger productive age population in the past (Hübelová, 2014a). The current onset of aging of the population is also shown by its high dynamics expressed by the changed aging index (Fig. 5). Attenuation of the traditional economic activities, as well as insufficient transport, social and healthcare infrastructures in these districts leads to above-average emigration and unemployment, in effect leading to negative changes in the demographic and socio-economic structure of the population. These districts are characterised not only by a lack of job opportunities but also, in many cases, by a lack of qualified and willing workforce, paradoxically enough. Moreover, the spatial concentration of individuals dependent on social allowances (expressed by housing allowances) creates, in the long-term horizon, the risk of development of poverty and social exclusion pockets (Hübelová, 2014c).

Cluster 2 tends to be the "average" cluster on both characteristics. Virtually all SMR were part of this

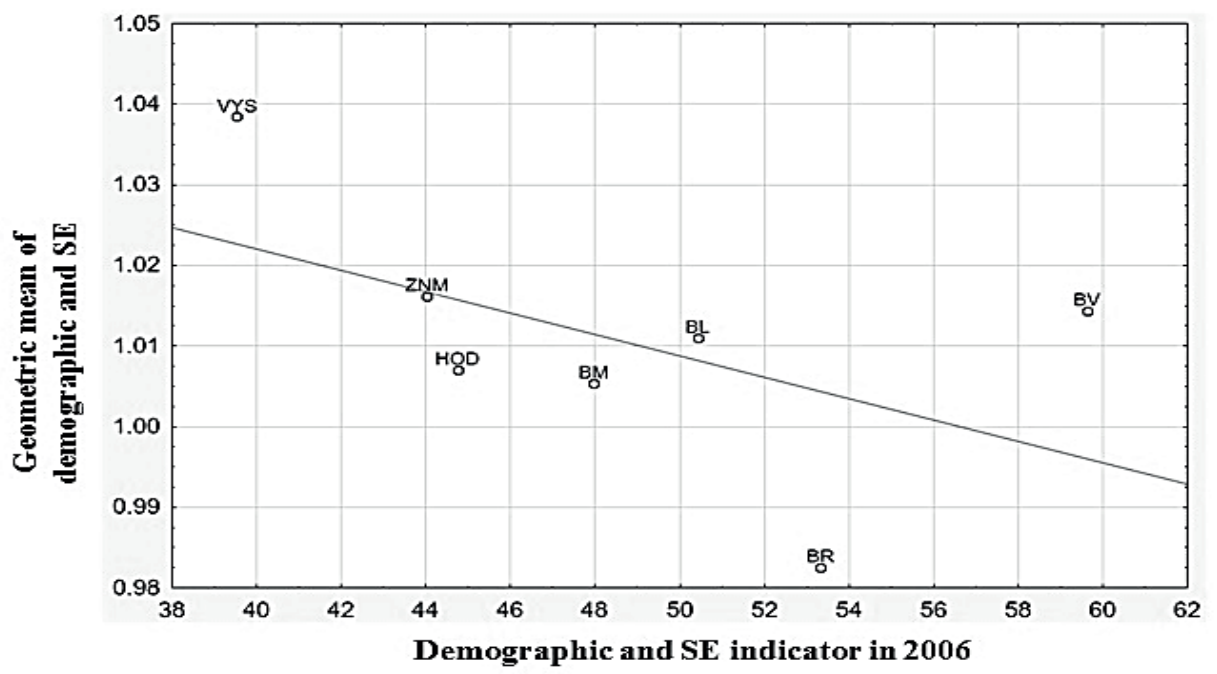

3: Line plot of standard deviations (districts of the South Moravian Region in 2006-2015) Source: own elaboration

II: Cluster composition (districts of the South Moravian Region in 2006-2015)

\begin{tabular}{ll}
\hline Cluster 1 & BM (2013, 2014), BR (2012, 2014), HOD (2013, 2014), ZNM (2011, 2013, 2014) \\
Cluster 2 & BL (2011, 2012, 2013, 2014, 2015), BM (2011, 2015), BV (2006, 2011, 2012, 2013), BR (2010, 2011, 2013), \\
& HOD (2008, 2012), VYS (2009, 2011, 2012, 2013, 2014, 2015), ZNM (2008, 2009, 2012, 2015) \\
Cluster 3 & BL (2007), BV (2007, 2008, 2009, 2010, 2014, 2015), BR (2007, 2008), VYS (2007, 2008, 2010), ZNM (2007) \\
\multirow{2}{*}{ Cluster 4 } & BL (2006, 2008, 2009, 2010), BM (2006, 2007, 2008, 2009, 2010, 2012), BR (2006, 2009), HOD (2006, 2007, \\
\hline
\end{tabular}

Source: own elaboration 


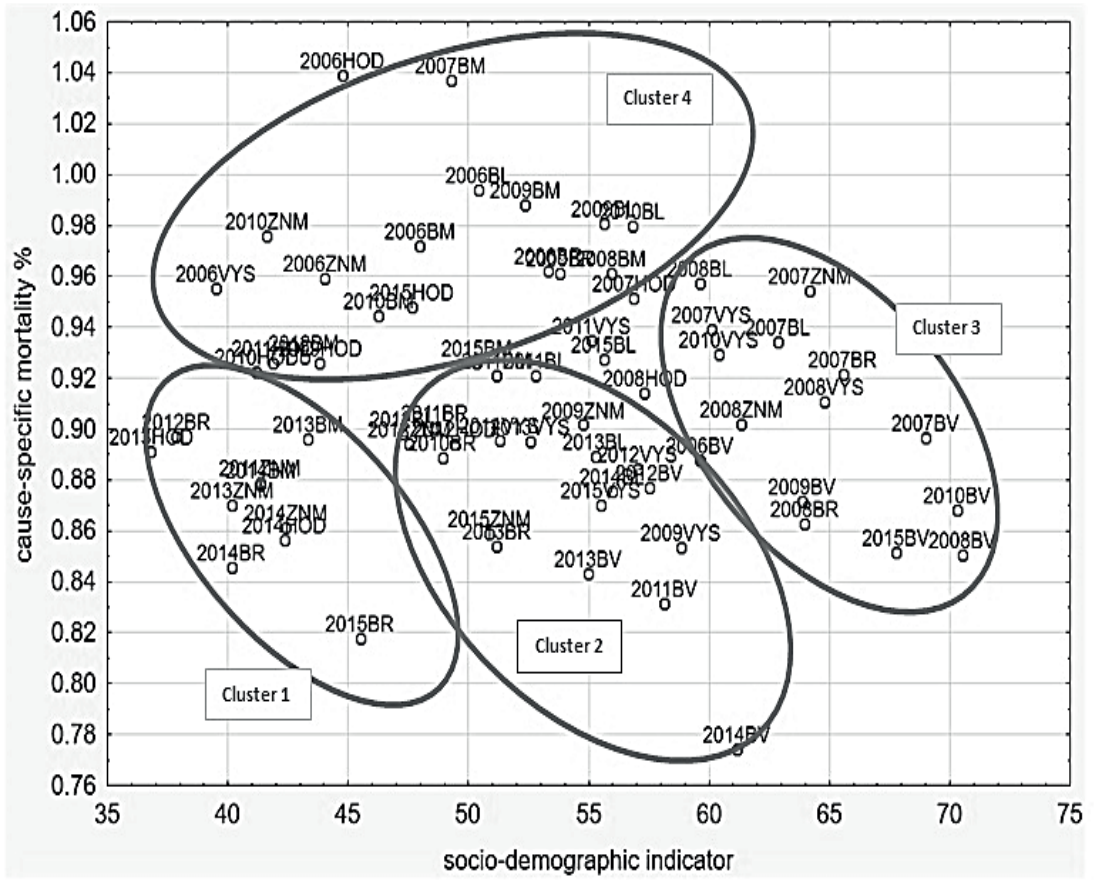

4: Profile diagram SE indicator and cause-specific mortality (districts of the South Moravian Region in 2006-2015)

Source: own elaboration

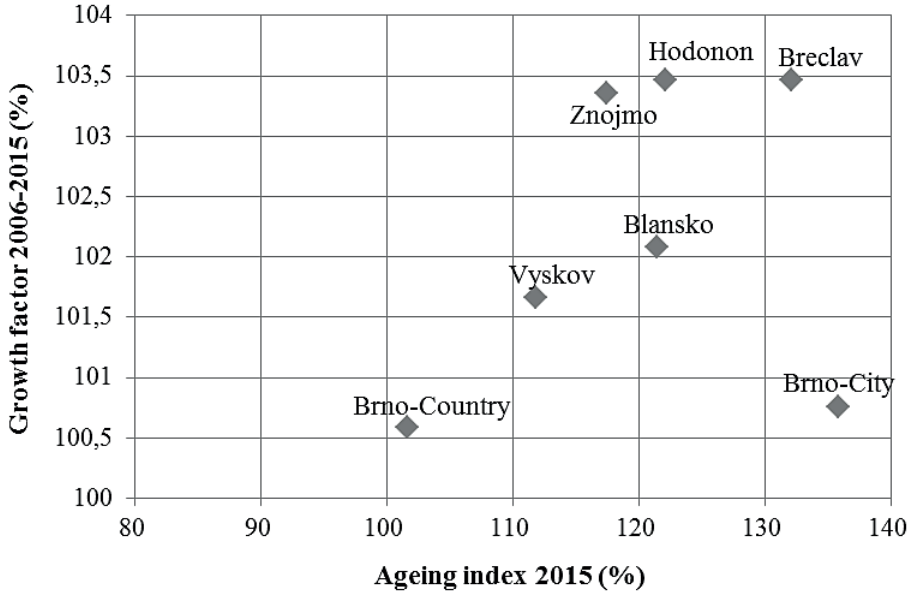

5: Aging index in 2015 and aging dynamics (districts of the South Moravian Region in 2006-2015)

Source: own elaboration, data of the Czech Statistical Office, 2016

cluster in different periods. The most frequently included districts were VYS (6 years) and BL ( 5 years of the studied 10 -calendar-year period). The calendar years in this cluster rather belong to the latter half of the monitored period (i.e. 2011-2015). This indicates the continuous improvement of the demographic and SE indicators in both districts, confirmed by the above mentioned convergence, also pointing to a positive development of mortality by the cause-specific death rate in VYS district. Thanks to the relatively favourable age structure of the population the aging index of this district is below-average and so are the aging dynamics
(Fig. 5), which is positively manifested also in other demographic and SE indicators (favourable indicators of the abortion/livebirth ratio and mortality levels by cause-specific death rate, low unemployment rate etc.). Aging dynamics determine the aging rate and are calculated as the average growth coefficient. The region may have a low age index, but if it has high aging dynamics, the age index will increase very quickly in the near future. The positive development trend observed can be attributed to the effect of suburbanisation with the good transport connection to the regional capital of Brno. 
As for cluster 3, the most favourable demographic and SE profile along with the below average cause-specific mortality is typical. This cluster is characteristic mainly for the BV district, situated in the background of the regional capital and thus affected by the suburbanisation trend in the development of its demographic and SE indicators. This district is a dynamic and perspective territory with a low aging index, a positive migration balance, a high proportion of the university graduate population and a low unemployment rate (Hübelová, 2014c). These factors in effect positively influence the below-average mortality rate by the cause-specific death rate.

Cluster 4 exhibits opposite behaviour than cluster 3, that is, above average cause-specific mortality and below-average demographic and SE profile. This cluster may be seen as the worst with the most frequent representation by the districts of HOD and especially BM, in fact across the calendar years of the analysed period 2006-2015. The HOD District was already commented on in the context of cluster 1 , but is most typical for cluster 4, together with the Brno-City District. The situation in the BM District may be assumed to be caused by the age structure with the typical high aging index, in harmony with the age group proportion development in all regional capitals of the country in the context of the suburbanisation trend. As a consequence of this, there is also an unfavourable development of the mortality growth coefficients in relation to the cause-specific death rate in the period 2006-2015 with the simultaneous growth of the housing allowance rate (Hübelová et al., 2017). In the whole complex action of the defined factors, the BM District is classified as the district with negative demographic and SE indicators and unsatisfactory mortality rates by the cause-specific death rate.

\section{DISCUSSION}

SE determinants often represent limiting factors which might be prevented by reasonable measures and their existence is manifested by health inequalities (Marmot et al., 2008). Countries with a generous system of social protection build a better health of their populations including a lower excessive mortality of seniors and a lower mortality of the socially disadvantaged groups (Lundberg et al., 2008). From the national economy perspective health, morbidity as well as changes in development of death-causing diseases represent a significant potential for use and development of the human capital (Becker, 1993). The economic effects of health may also be viewed in the context of mortality, representing one of the main factors of the health condition of the population and forming the basis for public policies in EU countries. This fact is also noted by the White Book by formulation of the following principle: "Health is the greatest wealth, the basic condition of economic productivity and prosperity" (EC 2007). Further general conclusions will require more detailed analysis for the investigated indicators are affected by additional external inputs, such as air quality (Marmot et al., 2008; OECD, 2013; Lakes et al., 2014) or availability of healthcare (Doorslaer et al., 2006; Avendano et al., 2009). The above-mentioned analyses confirmed the effect of demographic and socio-economic indicators on the structure of mortality and in the given context also on the health condition of the population.

The population mortality indicator is an important factor in demographic processes and analyses of mortality structure represent one of the main values showing health condition of the population. The health, morbidity and mortality of the population are affected by a complex of interactions between individual approach to health, economic factors and the social standards of the community (Pinto et al., 2016), as well as environmental determinants (Kruize, 2007; Lakes et al., 2014). Clearly, a summary grasp of all effects preconditioning mortality is difficult. Despite that, the above mentioned results show that there are systematic and at the same time territorial differences determining the structure of mortality of different population groups - the determinant of health. Our research has confirmed that there is an association between demographic and SE indicators and mortality by the man causespecific death rate (Fraser and Geogre, 2015). The lower living standards expressed by the housing allowance indicator and the unemployment rate prove the significant effect of these indicators as determinants of health inequality (Marmot et al., 2008). Our research has shown that the districts with a higher rate of housing allowances and above-average unemployment rate at the same time show worse demographic indicators, most likely manifested by worsening health condition reflected in the mortality rates by cause of death (Lemstra et al., 2015). The below-average values of demographic and SE indicators mean an increased mortality rate by cause-specific death rate, visible on the district level. The insufficient addressing of SE determinants of health is connected for example with a reported higher prevalence of circulatory system diseases (McGuinness et al., 2012), use of healthcare services and increased economic costs (Lee et al., 2009). 


\section{CONCLUSION}

The results of the composite indicator and the beta-convergence jointly indicate that positive development of both the demographic and the socio-economic factors in the years 2006-2015 was mainly achieved by the Vyškov District (the composite indicator growing by more than 15; the geomean 1.038) and the Brno-Country District (the composite indicator growing by nearly 8; convergence geo-mean 1.014), on the other hand, negative development was noticed in the Břeclav District (decrease of the composite indicator by 7; convergence geo-mean 0.983). The cluster analysis was based on four clusters: cluster 1 (Břeclav, Hodonín and Znojmo districts) showed district unification in the latter part of the period, in 2012-2014, and below-average values of the demographic and the socio-economic indicators with a relatively favourable mortality rate based on causes of death; cluster 2 (districts of Blansko and Vyškov) was classified as average; cluster 3 (mainly including the Brno-Country District) was seen as the best and cluster 4 (mainly including the Brno-City District) as the worst with below-average values of demographic as well as socio-economic factors and increased mortality rate based on the cause-specific death rate.

Based on the results of the analyzes and findings, it can be concluded that the following are predominantly responsible for the territorial disparities of the mortality structure and sociodemographic indicators:

Geographical location - the location of the district is associated with different natural and especially climatic conditions and is closely related to transport infrastructure. In the SMR districts, especially Znojmo and Hodonín, located in the area of the outer periphery, a worsening of the mortality structure as well as demographic and socio-economic indicators is occurring.

Distance from the regional city - the potential of using the easily accessible job and social opportunities of the city, commuting to work, to a doctor or other services, as evidenced by a positive change in indicators for Brno-Country and Vyškov Districts and the stable situation in Brno-City District socio-demographic indicators. On the contrary, the distance from the core area was again negatively reflected in the Znojmo, Hodonín and Břeclav Districts.

The degree of (sub) urbanization - suburbanization significantly affects socio-demographic characteristics, the population in suburban areas is characterized by a lower age index and higher educational structure, which is also reflected in the structure of mortality and socio-demographic characteristics of individual districts. When comparing the results for the districts of the South Moravian Region, the statement applies without exception in the Brno-Country and Vyškov Districts, where suburbanization is leading to a significant rejuvenation of the age structure, which in turn means an improvement in the level of mortality structure.

Educational structure - the level of educational attainment currently plays a decisive role in involvement in economic and social life and affects the quality of life of an individual. This corresponds to the unemployment rate indicator, but also secondarily to the educational level of the districts of the South Moravian Region, where the best results were achieved by the districts of BrnoCity, Brno-Country and Vyškov.

We wanted to objectively choose the main indicators that can influence mortality from the publicly available databases. These indicators can be evaluated using different statistical methods at the level of the lower territorial regions. Such an approach could be useful in planning the expenditure of public administration on social, public health and other areas. Critical assessment of the study - the indicator and time period selection might be questioned but both were determined by the limited data availability. For example, we do not use the indicator of life expectancy at birth, because at the level of the districts of the Czech Republic it is not constructed annually, but only for a time period (currently for 2013-2017). Another research direction is to extend the study to environmental factors.

\section{Acknowledgements}

This work was supported by the Internal Grant Agency of the Faculty of Regional Development and International Studies (Mendel University in Brno) Funding Agency under Grant [No. 2018/013] "Socio-demographic and environmental factors of the development and incidence of non-infectious diseases in the Czech Republic”. 


\section{REFERENCES}

ARRUDA, G. O., SANTOS, A. L., TESTON, E. F. et al. 2015. Association between self-reported health and sociodemographic characteristics with cardiovascular diseases in adults. Revista Da Escola De Enfermagem Da USP, 49(1): 60-67.

AVENDANO, M., GLYMOUR, M. M., BANKS, J. et al. 2009. Health disadvantage in US adults aged 50 to 74 years: A comparison of the health of rich and poor Americans with that of Europeans. American Journal of Public Health, 99(3): 540-548.

BARTON, H. and GRANT, M. 2006. A Health Map for the Local Human Habitat. The Journal for the Royal Society for the Promotion of Health, 126(6): 252-253.

BECKER, G. 1993. Human capital: a theoretical and empirical analysis, with special reference to education. Chicago: University of Chicago Press.

BORRELL, C., PONS-VIGUÉS, M., MORRISON, J. et al. 2013. Factors and Processes Influencing Health Inequalities in Urban Areas. Journal of Epidemiology and Community Health, 67(5): 389-391.

BÖRSCH-SUPAN, A., BRANDT, M., HUNKLER, C. et al. 2013. Data Resource Profile: The Survey of Health, Aging and Retirement in Europe (SHARE). International Journal of Epidemiology, 42(4): 9921001.

BRANDT, M., DEINDL, C. and HANK, K. 2012. Social Science \& Medicine Tracing the origins of successful aging: The role of childhood conditions and social inequality in explaining later life health. Social Science \& Medicine, 74(9): 1418-1425.

BRUTHANS, J. 2000. Report on development of cardiovascular diseases in the Czech Republic after 1989. Prague: Galén.

CLARK, R. 2011. World health inequality: convergence, divergence, and development. Social Science \& Medicine, 72(4): 617-624.

CSO. 2016a. Statistical Yearbook of the South Moravian Region. Prague: Czech Statistical Office. [Online]. Available at: https://www.czso.cz/csu/xb/casove_rady [Accessed: 2018, 28 March 28].

CSO. 2016b. Selected demographic data by district. Prague: Czech Statistical Office. [Online]. Available at: https://www.czso.cz/csu/xb/okresy [Accessed: 2018 February 25].

CSO. 2016c. Living conditions, Household Income and Expenditure. Prague: Czech Statistical Office. [Online]. Available at: https://vdb.czso.cz/vdbvo2/faces/cs/index.jsf?page=vystupobjekt\&pvo=SZB0 2D\&Z=T\&f=TABULKA\&katalog=31737\&str=v67\&\&c=v4 8_RP2015\#w [Accessed: 2017, March 4].

DAHLGREN, G. and WHITEHEAD, M. 1991. Policies and Strategies to Promote Social Equity in Health. Stockholm: Institute for Future Studies.

DELANEY, L., MCGOVERN, M. and SMITH, J. P. 2011. From Angela's ashes to the Celtic tiger: early life conditions and adult health in Ireland. Journal of Health Economics, 30(1): 1-10.

ĎURČEK, P. and RICHTER, M. 2014. Development of Selected Demographic Indicators in the Context of Urban Shrinkage Phenomenon in the Urban Space of Slovakia. Geographia Cassoviensis, 8(2): 127-140.

EC. 2007. Together for Health: A Strategic Approach for the EU 2008-2013. [Online]. Brussels: European Commission. Available at: http://ec.europa.eu/health/ph_overview/Documents/strategy_wp_en.pdf [Accessed: 2018, April 5].

EC. 2012. European Commission - ECHI European Core Health Indicators. [Online]. Brussles: European Commission. Available at: http://ec.europa.eu/health/indicators/echi/list/index_en.htm [Accessed: 2017, March 20].

FRANK, J. W., COHEN, R., YEN, I. et al., 2003. Socioeconomic gradients in health status over 29 years of follow-up after midlife: The Alameda county study. Social Science \& Medicine, 57(12): 2305-2323.

FRASER, S. D. S. and GEORGE, S. 2015. Perspectives on differing health outcomes by city: Accounting for Glasgow's excess mortality. Risk Management and Healthcare Policy, 8: 99-110.

FRIJTERS, P., HATTON, T. J., MARTIN, R. M., SHILEDS, M. A. 2010. Childhood economic conditions and length of life: evidence from the UK Boyd Orr cohort, 1937-2005. Journal of Health Economics, 29(1): 39-47.

GALOBARDES, B., LYNCH, J. W. and SMITH, G. D. 2004. Childhood socioeconomic circumstances and cause-specific mortality in adulthood: Systematic review and interpretation. Epidemiologic Reviews, 26(1): 7-21.

HAVEMAN-NIES, A., DE GROOT, L., VAN STAVEREN, W. A. 2003. Dietary quality, life-style factors and healthy aging in Europe: the SENECA study. Age and Aging, 32(4): 427-434.

HÜBELOVÁ, D. 2014a. Some results of comparison of the quality of human resources in the districts of the Czech Republic. Geographical Journal, 66(4): 383-400.

HÜBELOVÁ, D. 2014b. Geodemografická analýza disparit kvality lidských zdrojů v České republice. Brno: Mendel univerzity in Brno. 
HÜBELOVÁ, D. 2014c. Regional Disparities of the Human Resources Quality of the Czech Republic in the Context of Demographic and Economic Development. Geographia Cassoviensis, 8(1): 34-49.

HÜBELOVÁ, D., JADCZAKOVÁ, V. and ROUSOVÁ, G. 2017. Impact of demographic and socioeconomic determinants on mortality in districts of the South Moravian region in 2006-2015. In: KLÍMOVÁ V. and ŽÍTEK, V. (Eds.). Proceedings of the $20^{\text {th }}$ International Colloquium on Regional Sciences. Brno: Masaryk University, pp. 396-405.

IHIS CR. 2015. Deaths 2013. Prague: IHIS CR.

IHIS CR. 2016. Czech Health Statistics Yearbook 2015. Prague: IHIS CR.

JÜRGES, H. 2007. True health vs. response styles: exploring cross-country differences in self-reported health. Health Economics, 16(2): 163-178.

KHANG, Y. H., YANG, S., CHO, H. J., JUNG-CHOI, K., YUN, S. C. 2010. Decomposition of socioeconomic differences in life expectancy at birth by age and cause of death among 4 million South Korean public servants and their dependents. International Journal of Epidemiology, 39(6): 1656-1666.

KRUIZE, H. 2007. On Environmental Equity: Exploring the Distribution of Environmental Quality Among Socio-Economic Categories in The Netherlands. Netherlands Geographical Studies 359. Utrecht: Koninklijk Nederlands Aardrisjkskundig Geonootschap.

LAKES, T., BRÜCKNER, M. and KRÄMER, A. 2014. Development of an environmental justice index to determine socio-economic disparities of noise pollution and green space in residential areas in Berlin. Journal of Environmental Planning and Management, 57(4): 538-556.

LEE, D. S., CHIU, M., MANUEL, D. G., TU, K., WANG, X. and AUSTIN, P. C. 2009. Trends in risk factors for cardiovascular disease in Canada: temporal, socio-demographic and geographic factors. Canadian Medical Association Journal, 181(3-4): 55-66.

LEMSTRA, M., ROGERS, M., MORAROS, J. 2015. Income and heart disease: Neglected risk factor. Canadian Family Physician, 61(8): 698-704.

LUCK, J., CHANG, C., BROWN, E. R. and LUMPKIN, J. 2006. Using Local Health Information to Promote Public Health. Health Affairs, 25(4): 979-991.

LUNDBERG, O., ÅBERG YNGWE, M., KÖLEGÅRD STJÄRNE, M. et al. 2008. The Nordic Experience: Welfare States and Public Health (NEWS): health equity studies No 12 - report for the Commission on Social Determinants of Health. Stockholm: Centre for Health Equity Studies (CHESS).

LUNDQUIST, J., ANDERTON, D. and YAUKEY, D. 2014. Demography: The Study of Human Population. Illinois: Waveland Press.

MARMOT, M. and BELL, R. 2012. Fair society, healthy lives. Public Health, 126(1): 4-10.

MARMOT, M., FRIEL, S., BELL, R. and HOUWELING, T. A. J. 2008. Closing the gap in a generation: health equity through. The Lancet, 372(9650): 1661-1669.

MATTHEWS, R. J., SMITH, L. K., HANCOCK, R. M., JAGGER, C. and SPIERS, N. A. 2005. Socio-economic factors associated with the onset of disability in older age: a longitudinal study of people aged 75 years and over. Social Science \& Medicine, 61(7): 1567-1575.

McGUINNESS, D., McGLYNN, L. M., JOHNSON, P. C. D., MACINTYRE, A., BATTY, G. D., BURNS, H. and SATTAR, N. A. 2012. Socio-economic status is associated with epigenetic differences in the pSoBid cohort. International Journal of Epidemiology, 41(1): 151-160.

MCLAUGHLIN, S. J., CONNELL, C. M., HEERINGA, S. G., LI, L. W. and ROBERTS, J. S. 2010. Successful aging in the United States: prevalence estimates from a national sample of older adults. Journal of Gerontology: Social Sciences, 65B(2): 216-226.

MINICUCI, N., NAIDOO, N., CHATTERJI, S. and KOWAL, P. 2016. Data Resource Profile: Cross-national and cross-study sociodemographic and health-related harmonized domains from SAGE plus ELSA, HRS and SHARE (SAGE+, Wave 1). International Journal of Epidemiology, 45(5): 1403-1403.

MINISTRY OF HEALTH CR. 2014. Report on the Health of the Population of the Czech Republic. Prague: Ministry of Health of the CR.

MUNIZ, L. C., SCHNEIDER, B. C., DA SilVA, I. C. M., MATIJASEVICH, A. and SANTOS, I. S. 2012. Accumulated behavioral risk factors for cardiovascular diseases in Southern Brazil. Revista de Saúde Pública, 46(3): 534-542.

NIPH. 2015a. Environmental Health Monitoring System in the Czech Republic - Summary Report 2012. Prague: NIPH.

NIPH. 2015b. Health, Life Style and Environment 2014. Prague: NIPH.

NORSKER, F. N., ESPENHAIN, L., ROGVI, S., MORGEN, C. S., ANDERSEN, P. K., NYBO ANDERSEN, A.M. 2012. Socioeconomic position and the risk of spontaneous abortion: a study within the Danish National Birth Cohort. BMJ Open, 2(3): 1-7.

OECD. 2013. Health at a glance 2013: OECD Indicators. Paris: OECD Publishing.

OUŘEDNÍČEK, M., TEMELOVÁ, J. and POSPÍŠILOVÁ, L. 2011. Atlas of Socio-spatial Differentiation of the Czech Republic. Prague: Nakladatelství Karolinum. 
PAVLÍK, I., HÜBELOVÁ, D. and KONEČNÝ, O. 2017. Contribution to Health Geography: Sources of the contamination of surface waters and health risks in the Moravian Karst Protected Landscape Area. Geographia Cassoviensis, 11(1): 33-50.

PINTO, D. A., GLATTSTEIN-YOUNG, G., MOHAMED, A., BLOCH, G., LEUNG, F. and GLAZIER, R. H. 2016. Building a Foundation to Reduce Health Inequities: Routine Collection of Sociodemographic Data in Primary. The Journal of the American Board of Family Medicine, 29(3): 348-355.

PORTRAIT, F., ALESSIE, R. and DEEG, D. 2010. Do early life and contemporaneous macro- conditions explain health at older ages? Journal of Population Economics, 23(2): 617-642.

PRUCHNO, R. A., WILSON-GENDERSON, M., ROSE, M. and CARTWRIGHT, F. 2010. Successful aging: early influences and contemporary characteristics. The Gerontologist, 50(6): 821-833.

SHKOLNIKOV, V. M., ANDREEV, E. M., LEON, D. A., MCKEE, M., MESLÉ, F. and VALLIN, J. 2004. Mortality Reversal in Russia the story so far. Hygiea Internationalis an Interdisciplinary Journal for the History of Public Health, 4(1): 29-80.

SUBRAMANIAN, S. V. and KAWACHI, I. 2004. Income inequality and health: what have we learned so far? Epidemiologic Reviews, 26(1): 78-91.

SWIFT, R. 2011. The relationship between health and GDP in OECD countries in the very long run. Health Economics, 20(3): 306-322.

TOBIASZ-ADAMCZYK, B., BRZYSKI, P., GALAS, A., BRZYSKA, M. and FLOREK, M. 2011. Relationship between characteristics of social network, health-related quality of life and mortality patterns in older age. Krakow study. Journal of Epidemiology \& Community Health, 65: 215-215.

TORRE, R. and MYRSKYLÄ, M. 2011. Income inequality and population health: An Analysis of Panel Data for 21 Developed Countries, 1975-2006. Population Studies, 68(1): 1-13.

VAN DEN BERG, G. J., LINDEBOOM, M., LOPEZ, M. 2009. Inequality in individual mortality and economic conditions earlier in life. Social Science \& Medicine, 69(9): 1360-1367.

VAN DOORSLAER, E., MASSERIA, C. and KOOLMAN, X. 2006. Research Inequalities in access to medical care by income. Canadian Medical Association Journal, 174(2): 177-183.

VEUGELERS, P. J., YIP, A. M. and MO, D. 2001. The north-south gradient in health: analytic applications for public health. Canadian Journal Public Health, 92(2): 95-98.

WARD, M. M. 2012. Sense of control and sociodemographic differences in self-reported health in older adults. Quality of Life Research, 21(9): 1509-1518.

WHITEHEAD, M. and DAHLGREN, C. 1991. What can we do about inequalities in health? The Lancet, 338(8774): 1059-1063.

WHO. 2011. International Statistical Classification of Diseases, 10 Revision. Geneva: WHO.

Dana Hübelová: dana.hubelova@mendelu.cz

Alice Kozumplíková: alice.kozumplikova@mendelu.cz 